\title{
Enfermedades pleurales benignas inducidas por asbesto
}

\section{Benign pleural diseases induced by asbestos}

\section{J. Boldú, V. M. Eguía}

\section{RESUMEN}

La exposición al asbesto es una causa importante de patología pleural y se puede producir con intensidades moderadas o ligeras dada la capacidad del asbesto de concentrarse en la pleura. Ello motiva junto a la prolongada latencia existente entre la exposición y la enfermedad, que sigamos viendo durante muchos años manifestaciones clínicas pleurales de exposición previa, a pesar del uso del asbesto cada vez más limitado en las últimas décadas. Dicha exposición puede presentarse con distintas manifestaciones tanto malignas como el mesotelioma como benignas, siendo las principales de éstas el derrame pleural benigno, las placas pleurales, la fibrosis pleural difusa y la atelectasia redonda.

Palabras clave. Asbesto. Pleura. Benigna.

\begin{abstract}
Exposure to asbestos is an important cause of pleural pathology and can be produced with light or moderate tendencies given the capacity of asbestos to concentrate in the pleura. Together with the prolonged latency existing between exposure and the disease, this means that for many years we will continue to see pleural clinical manifestations from past exposure, in spite of the increasingly limited use of asbestos in recent decades. This exposure can show itself in different manifestations, both malign, such as mesothelioma, and benign, principally benign pleural effusion, pleural plaques, diffuse pleural fibrosis and massive atelectasis.
\end{abstract}

Key words. Asbestos. Pleura. Benign.

An. Sist. Sanit. Navar. 2005; 28 (Supl. 1): 21-28.

Sección de Neumología. Hospital Virgen del Camino. Pamplona.

\author{
Correspondencia: \\ Joan Boldú Mitjans \\ Sección de Neumología \\ Hospital Virgen del Camino \\ Irunlarrea, 4 \\ 31008 Pamplona \\ Tfno. 848429660 \\ e-mail: jboldumi@cfnavarra.es
}




\section{INTRODUCCIÓN}

La exposición al asbesto, dada su especial afinidad por la pleura, es una causa importante de patología pleural. Puede presentarse con distintas manifestaciones, sin que esté aclarado por qué en distintos pacientes es capaz de inducir trastornos malignos como el mesotelioma, procesos fibrosantes como las placas pleurales benignas, o inflamatorios con exudación como el derrame pleural benigno. No se ha podido demostrar claramente la asociación de un tipo determinado de afectación con un tipo determinado de fibras de asbesto, o con factores individuales objetivos de susceptibilidad. Sí se ha demostrado una relativa asociación con el grado de exposición. De tal forma, que con las sucesivas restricciones a su uso industrial en las dos últimas décadas, las enfermedades asociadas a un mayor grado de exposición como es la asbestosis, se van observando cada vez menos. En cambio, la patología pleural en sus diversas variantes tanto benigna en forma de placas pleurales, como maligna en forma de mesotelioma, se van convirtiendo en las patologías más frecuentes, al estar asociadas a un menor grado de exposición.

\section{¿CÓMO LLEGAN LAS FIBRAS A LA PLEURA?}

Se ha demostrado claramente la tendencia de las fibras de asbesto a acumularse en la pleura, tanto en animales de experimentación como en estudios de cuantificación de fibras en tejidos humanos de personas sólo expuestas o con enfermedades relacionadas con el asbesto. Las fibras pueden estar en líquido pleural tan precozmente como 7 días en modelos animales. En trabajadores expuestos, los contajes de fibras son mucho mayores en placas pleurales o en ganglios linfáticos que en parénquima, de donde tienden a migrar hacia la periferia ${ }^{1,2}$. La distribución de las fibras en la pleura es sobre todo en la hoja parietal, pero de forma irregular, agrupadas en focos, lo que explica las discordantes medidas de fibras en pleura en estudios distintos ${ }^{3}$. Son además de tamaño inferior a las encontradas en otras zonas.
Se desconoce el camino exacto de las fibras desde el exterior hasta la pleura, pero parece ser a través del espacio peribroncovascular intersticial del pulmón y a través de los linfáticos, dada la relativa baja resistencia tisular de estas zonas, y ayudadas por el gradiente de presión hacia el espacio subpleural que tiene presión subatmosférica.

La toxicidad del asbesto parece estar causada por una combinación de factores como son la forma de las fibras, la composición química y las características de su superficie.

\section{ENFERMEDADES PLEURALES RELACIONADAS CON EL ASBESTO}

Hay dos tipos:

- Benignas: placas pleurales, derrame pleural benigno por asbesto, fibrosis pleural difusa y atelectasia redonda.

- Malignas: mesotelioma.

\section{Placas pleurales (Figs. 1 y 2)}

Son lesiones fibrosas localizadas en la pleura parietal. Es la patología pleural más precoz después del derrame pleural benigno. Se pueden empezar a observar a los 15 años de la exposición, aunque son más comunes a partir de los 20-30 años. Son habitualmente asintomáticas, aunque sean relativamente extensas. Se trata de lesiones circunscritas formadas por tejido fibroso en pleura parietal, hipocelulares y colagenizadas, habitualmente múltiples y localizadas preferentemente en zonas intercostales laterales y posteriores, en pleura mediastínica y en cúpula diafragmática. Suelen respetar los ángulos costofrénicos y las zonas apicales. Este tejido fibroso está localizado entre la capa elástica de la pleura parietal y la capa mesotelial. Suelen ser bilaterales pero no simétricas y calcifican con frecuencia, sobre todo en lesiones de larga evolución. Las calcificaciones se inician como un punteado fino, irregular, que va coalesciendo y llegando a formar pequeñas placas densas, de 1 a $4 \mathrm{~cm}$ de longitud, de bordes irregulares. Pueden aparecer en la placa de tórax como imágenes suspendidas en la proyección postero- 

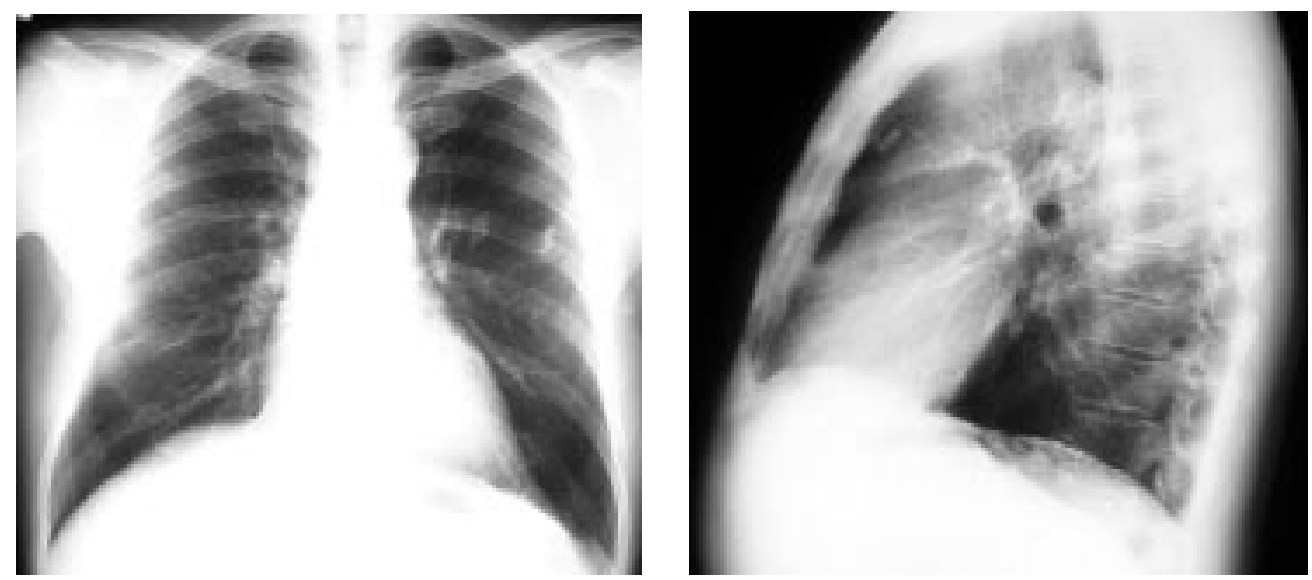

Figura 1. Imagen tenue, suspendida y calcificada en la Rx de tórax posteroanterior en LSI, que en la lateral se localiza retroesternal. También se aprecia una imagen calcificada lineal en la cúpula del hemidiafragma izquierdo en ámbas proyecciones, todo ello muy sugestivo de placas pleurales por asbesto.
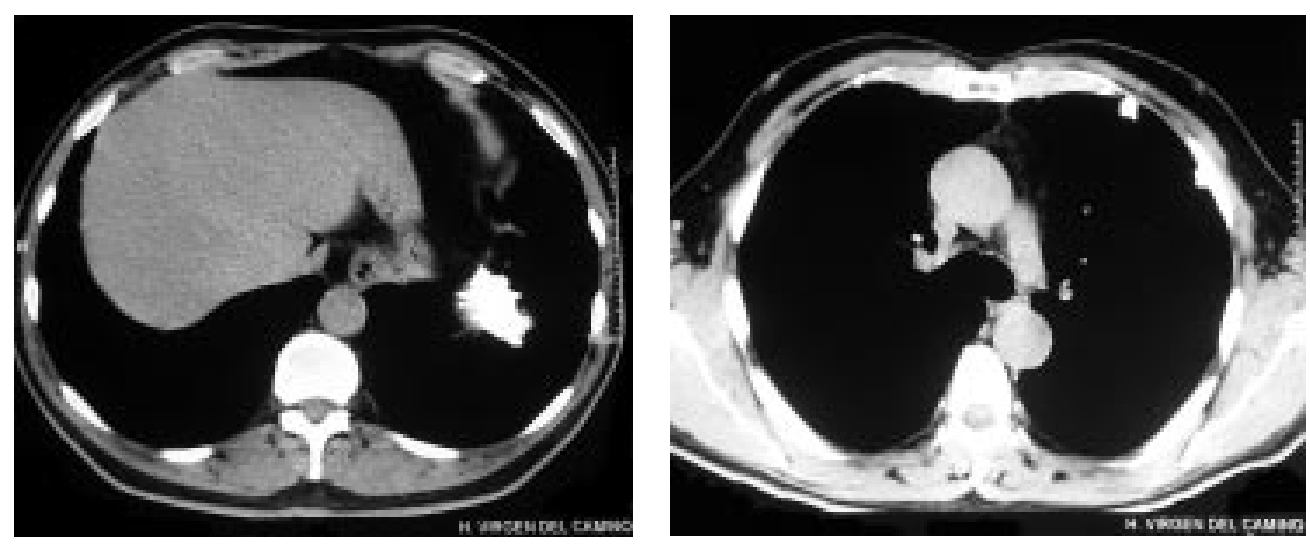

Figura 2. Cortes de tomografía axial computarizada del mismo paciente en que se observa la calcificación en cúpula diafragmática y las placas calcificadas en la pared anterolateral de hemitórax izquierdo.

anterior, que no se localizan o identifican en la lateral, o como lesiones lineales densas, dependiendo de la proyección. En la pleura diafragmática toman un aspecto característico lineal, que en ausencia de antecedentes de trauma previo, cirugía, tuberculosis o infección local significativas, son casi patognomónicas.

Pueden aparecen hasta en un $50 \%$ de los trabajadores expuestos, y en un $2,3 \%$ de la población general masculina de Esta- dos Unidos ${ }^{4}$, aumentando su incidencia con el número de años de exposición. Se consideran un marcador de la carga de exposición y su presencia puede aumentar el riesgo de padecer tanto asbestosis como mesotelioma ${ }^{4}$, en este caso no por degeneración maligna de la placa sino por el riesgo asociado a la carga de asbesto. Aunque son generalmente asintomáticas, se ha descrito afectación funcional leve en algunos pacientes, con disminución de la 
$\mathrm{FVC}$, incluso de la transferencia de $\mathrm{CO}$, sin enfermedad intersticial asociada, aunque estudios recientes con lavado broncoalveolar y TAC de alta resolución han sugerido que puede existir una alveolitis subclínica sugestiva de asbestosis incipiente como responsable de la alteración funcional.

Cabe destacar que las placas pleurales asociadas a la exposición al asbesto suelen ser un hallazgo radiológico incidental, y muchas veces su morfología es lo suficientemente característica como para sugerir el diagnóstico con alto grado de certeza en un contexto adecuado.

No tienen más importancia clínica que el ser un testigo de la exposición al asbesto y de la conveniencia de vigilar al paciente en el sentido de detectar otras patologías causadas por dicha exposición y que sí tengan repercusión clínica.

\section{Derrame pleural benigno por asbesto}

Es la manifestación más temprana de exposición al asbesto, pudiendo producirse antes de los diez años de la exposición. Se manifiesta como una pleuritis aguda, habitualmente unilateral, con derrame de pequeña o moderada cuantía, pero que puede durar varios meses. Se trata de un exudado a menudo serohemorrágico, con celularidad variable y glucosa normal. Puede asociarse a placas pleurales pero también puede ser la única manifestación de exposición. Puede ser de clínica solapada paucisintomática o en forma de cuadro agudo incluso febril, con dolor pleurítico, VSG elevada, etc. La biopsia pleural muestra una pleuritis reactiva inespecífica y muy esporádicamente pueden encontrarse cuerpos de asbesto en el líquido pleural. Puede persistir varios meses, hacerse bilateral o recidivar. A veces se descubre incidentalmente como un pinzamiento o un mínimo derrame asintomático. Su frecuencia puede ser de hasta un $7 \%$ de los trabajadores con exposiciones importantes ${ }^{5}$.

El diagnóstico es por exclusión de otras patologías pleurales que puedan presentarse así, con negatividad de las exploraciones diagnósticas, generalmente incluso tras una toracoscopia, en un contexto adecuado de exposición a asbesto, y tras un seguimiento obligado de 2-3 años para excluir patologías sobre todo tumorales que pudieran debutar así. El diagnóstico diferencial es particularmente delicado en la distinción del derrame por un mesotelioma pleural. El pronóstico es bueno y el derrame tiende a autolimitarse en la mayoría de pacientes en menos de 3 meses $^{6}$.

El derrame pleural benigno por asbesto es la manifestación más precoz de la exposición al asbesto. Puede manifestarse como un cuadro agudo o subagudo. El diagnóstico es por exclusión y tras seguimiento de 2-3 años. El pronóstico es bueno y se autolimita en varios meses.

\section{Fibrosis pleural difusa}

Se trata de una fibrosis pleural difusa, que en este caso, a diferencia de las placas, afecta a pleura visceral. Es una paquipleuritis extensa, colagenizada, a menudo bilateral que afecta a pleura visceral, con grosor que va de un milímetro a un centímetro o más, que puede extenderse a parénquima subpleural a través de los septos interlobulares y de las cisuras, incluso con tractos que pueden penetrar al pulmón. Se presenta con mucha menos frecuencia que las placas pleurales. Afecta con mucha frecuencia a los ángulos costofrénicos lo que también la distingue de las placas. Son frecuentes las adherencias a pleura parietal. Al contrario también de las placas pleurales, aquí sí que suele haber una afectación funcional importante en forma de trastorno restrictivo con disminución de la FVC, con menor descenso de la transferencia de $\mathrm{CO}$, repercusión en el intercambio gaseoso, en grado variable según la extensión. Se han descrito series de pacientes con insuficiencia respiratoria crónica secundaria, hipercápnia, cor pulmonale e incluso muerte sin evidencia de enfermedad parenquimatosa, sólo por la fibrosis pleural que conduce a lo que se ha venido en denominar pulmón atrapado ${ }^{7}$. En estos casos la decorticación puede ser de interés terapéutico.

Cabe destacar que la fibrosis pleural difusa es una forma de afectación pleural por asbesto con afectación funcional mucho más severa que las placas; es mucho menos frecuente y afecta a pleura visceral al contrario que las placas. Con fre- 
cuencia es extensa y bilateral y afecta característicamente a zonas respetadas por las placas pleurales (senos costofrénicos).

\section{Atelectasia redonda (Figs. 3, 4, 5, 6 y 7)}

La atelectasia redonda es el atrapamiento de una parte del pulmón subyacente a una superficie pleural afectada por un proceso fibrótico. La pleura esta invaginada sobre sí misma, atrapando el parénquima contiguo y llevando a los bronquios y vasos que van a dicha zona a dibujar una imagen curvilínea que radiológicamente se

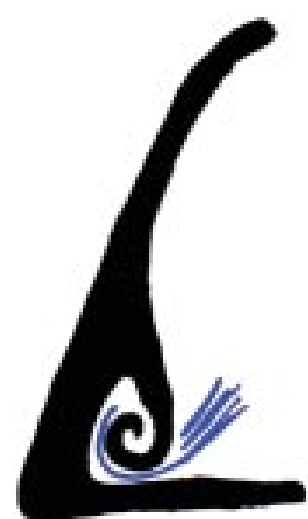

Figura 3. Esquema de cómo el parénquima pulmonar se repliega hacia el interior, obligado por la retracción de la fibrosis pleural, viéndose los vasos y los bronquios curvándose hacia el interior.
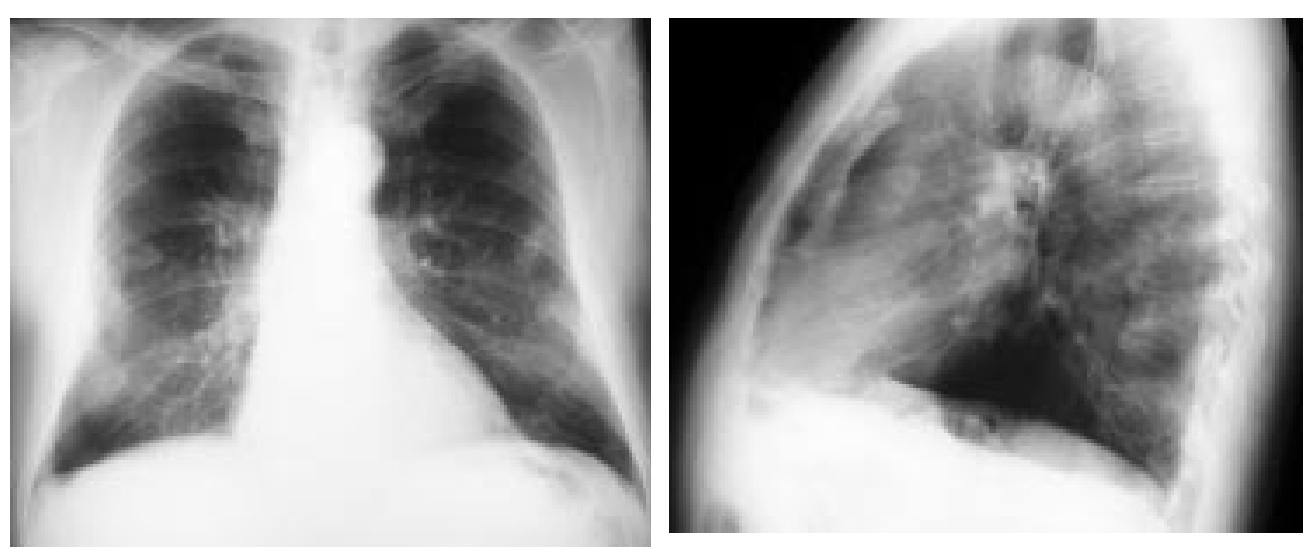

Figura 4. Afectación pleural extensa en paciente con exposición intensa a asbesto 35 años antes, con
distintos tipos de placas pleurales típicas, también zonas de fibrosis difusa y una atelectasia

Figura 4. Afectación pleural extensa en paciente con exposición intensa a asbesto 35 años antes, con
distintos tipos de placas pleurales típicas, también zonas de fibrosis difusa y una atelectasia redonda en base derecha. conoce como cola de cometa como dato mas característico (Fig. 3). Aparece como una masa redondeada, adyacente a la pleura. Otros datos radiológicos que ayudan a distinguirla de otro tipo de lesiones especialmente tumorales, son la forma en cuña o redondeada, el engrosamiento pleural asociado y la pérdida de volumen del lóbulo restante. Aunque teóricamente se puede ver en fibrosis pleurales de cualquier origen, en la práctica la mayoría de los casos están asociados a fibrosis pleural secundaria a exposición al asbesto ${ }^{8}$ ya sea en forma de fibrosis pleural difusa o de placas pleurales extensas y abigarradas. Es una entidad bastante infrecuente. No da otros síntomas que los asociados al grado de fibrosis pleural de base. El principal problema que genera es la dificultad de distinguirla de una lesión tumoral verdadera cuando no tiene la apariencia típica. Ante la duda es mejor la extirpación quirúrgica.

Cabe destacar que la atelectasia redonda es una anomalia que se ve con mayor frecuencia en las afectaciones fibróticas extensas provocadas por exposición al asbesto, aunque también se puede ver en otras fibrosis pleurales de otro origen.

Radiológicamente tiene una morfología muy característica que incluso puede ser patognomónica. Es asintomática habitualmente.

Ante dudas diagnósticas debe extirparse quirúrgicamente. 

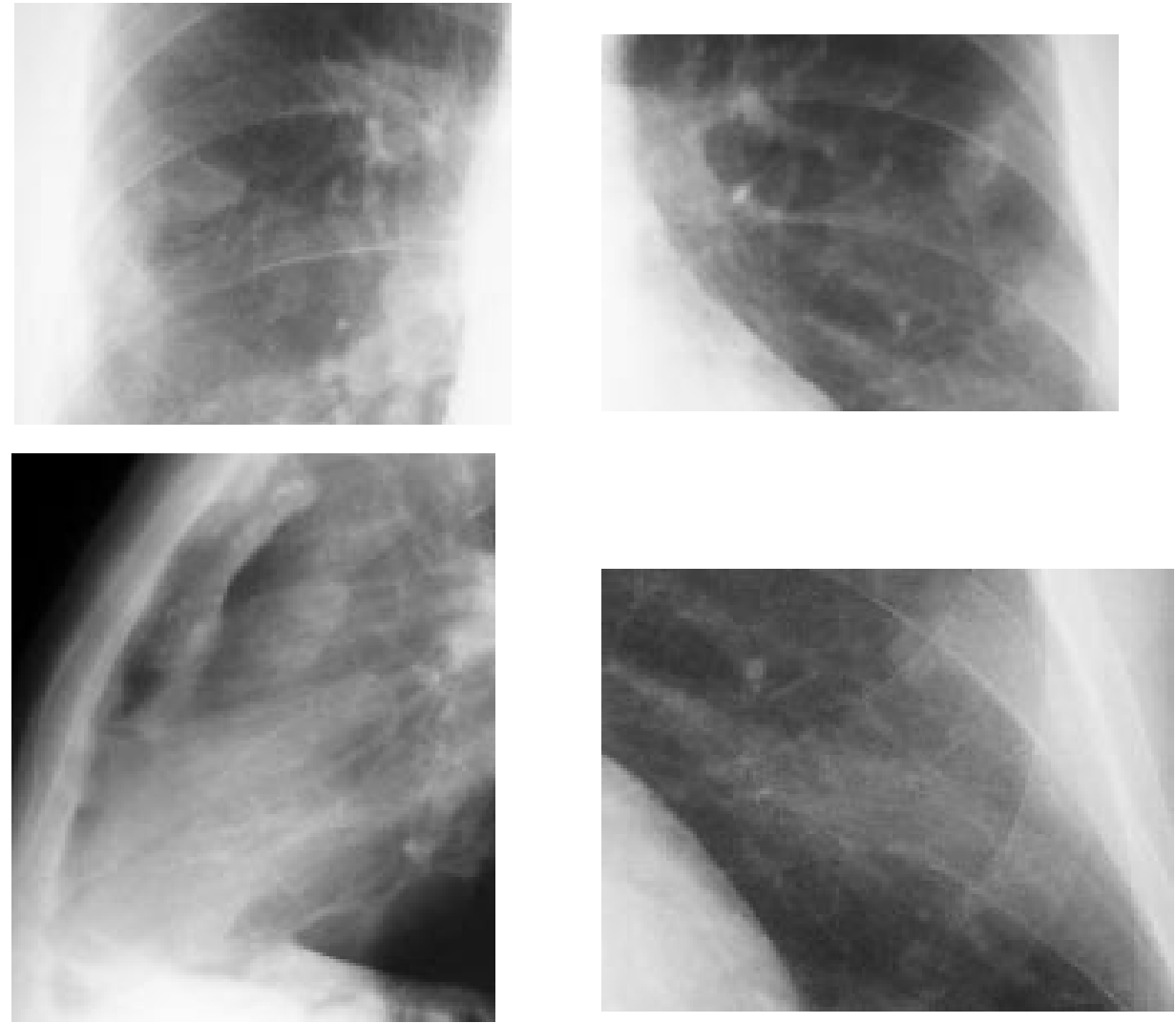

Figura 5. Imágenes de detalle del mismo paciente.
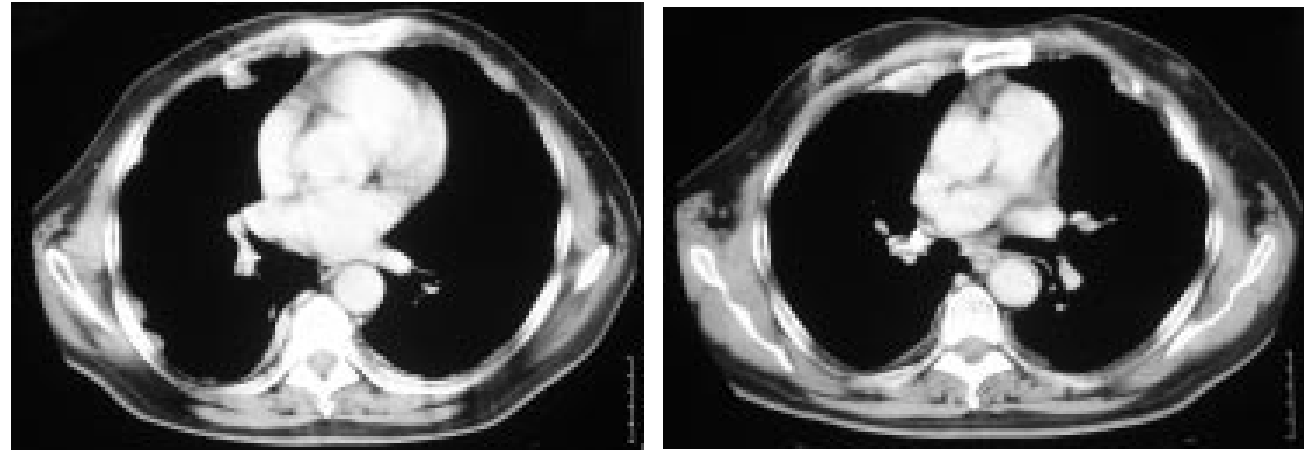

Figura 6. Imágenes de tomografía axial computarizada de las distintas placas pleurales en distintos territorios del mismo paciente. 

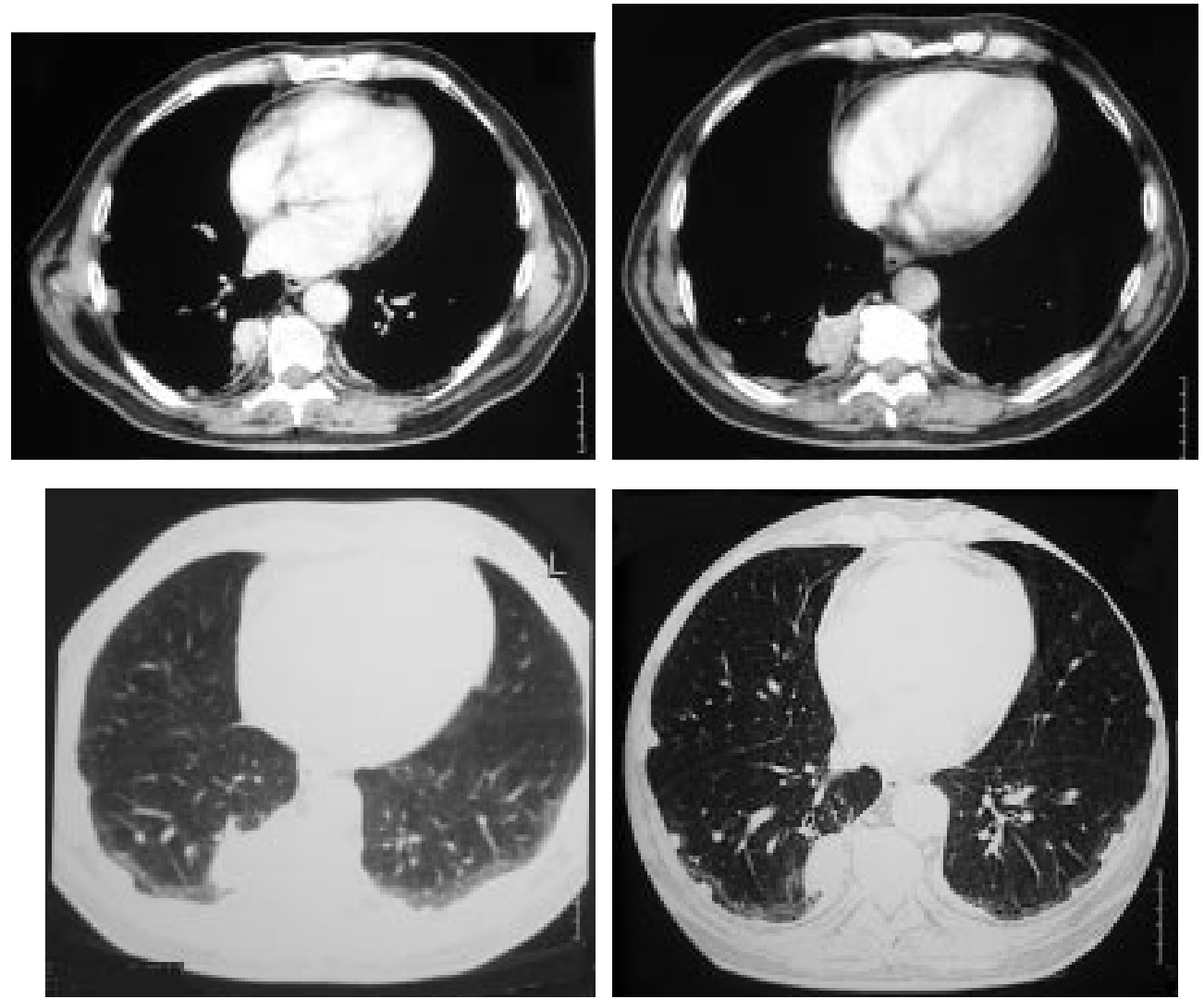

Figura 7. Imágenes de la atelectasia redonda basal.

\section{BIBLIOGRAFÍA}

1. Dodson RF, Williams MG, Corn CJ et al. Asbestos content of lung tissue, lymph nodes and pleural plaques from former shipyard workers. Am Rev Respiratory Dis 1990; 142: 843.

2. Viallat JR, Raybuad F, Passarel M, Boutin C. Pleural migration of chrysotile fibbers after intratracheal injection in rats. Arch Environ Health. 1986; 41: 282-286. Am J Respir Crit Care Med 1996; 153: 444-449.

3. Boutin C, Dumortier P, Rey F, Viallat JR, De VuYsT P. Black spots concentrate oncogenic asbestos fibbers in the parietal pleura. Thoracoscopic and mineralogic study.Hillerdal G. Rounded atelectasis. Clinical experience with 74 patients. Chest 1989; 95: 836-841.

4. Miller JA, ZuRlo JV. Asbestos plaques in a typical Veteran's hospital population. Am J Ind Med 1996; 30: 726-729.

5. Epler GR, Mcloud TC, Gaensler EA. Prevalence and incidence of benign asbestos pleural effusion in a working population. JAMA 1982; 247: 617-622.

6. Ferrer J, Balcells E, Orriols R, Villarino MA, DRoBNIC Z, MoREll F. Derrame pleural benigno por asbesto. Descripción de la primera serie en España. Med Clin (Barc) 1996; 107: 535538.

7. Miller A, Teirstein AS, SElikoff IJ. Ventilatory failure due to asbestos pleurisy. Am J Med 1983; 75: 911-919.

8. Hillerdal G, Henderson DW. Asbestos, asbestosis, pleural plaques and lung cancer. Scand J Work Environ Health 1997; 23: 93103. 